\title{
Molecular and Electrophysiological Characterization of Dorsal Horn Neurons in a GlyT2-iCre-tdTomato Mouse Line
}

This article was published in the following Dove Press journal: Journal of Pain Research

\author{
Xiaolan $\mathrm{He}^{1,2, *}$ \\ Peng Liu ${ }^{1,2, *}$ \\ Xiao Zhang ${ }^{1,2, *}$ \\ Zhenhua Jiang ${ }^{1,2}$ \\ Nan Gu ${ }^{1,2}$ \\ Qun Wang ${ }^{1,2}$ \\ Yan Lu (D) ${ }^{1,2}$ \\ 'Department of Pain Medicine, \\ ${ }^{2}$ Department of Anesthesiology \& \\ Perioperative Medicine, Xijing Hospital, \\ Fourth Military Medical University, Xi'an, \\ 7I0032, People's Republic of China \\ *These authors contributed equally to \\ this work
}

Purpose: Spinal glycinergic neurons function as critical elements of a spinal gate for pain and itch. We have recently documented that spinal $\mathrm{PKC} \gamma^{+}$neurons receive the feedforward inhibitory input driven by $\mathrm{A} \beta$ primary afferent. The glycinergic neurons control the excitability of $\mathrm{PKC}^{+}$neurons and therefore gate mechanical allodynia. However, a dynamic or electrophysiological analysis of the synaptic drive on spinal glycinergic interneurons from primary afferent fibers is largely absent. The present study was aimed to analyze the synaptic dynamics between spinal glycinergic interneurons and primary afferents using a genetic labeled animal model.

Materials and Methods: The GlyT2-P2A-iCre mice were constructed by the CRISPR/ Cas9 technology. The GlyT2-iCre-tdTomato mice were then generated by crossing the GlyT2-P2A-iCre mice with fluorescent reporter mice. Patch-clamp whole-cell recordings were used to analyze the dynamic synaptic inputs to glycinergic neurons in GlyT2-iCretdTomato mice. The distribution of GlyT2-tdTomato neurons in the spinal dorsal horn was examined by the immunohistochemistry method. The firing pattern and morphological features of GlyT2-tdTomato neurons were also examined by electrophysiological recordings and intracellular injection of biocitin.

Results: The GlyT2-P2A-iCre and GlyT2-tdTomato mice were successfully constructed. GlyT2-tdTomato fluorescence was colocalized extensively with immunoreactivity of glycine, GlyT2 and Pax2 in somata, confirming the selective expression of the transgene in glycinergic neurons. GlyT2-tdTomato neurons were mainly distributed in spinal lamina IIi through IV. The firing pattern and morphological properties of GlyT2-tdTomato neurons met the features of tonic central or islet type of spinal inhibitory interneurons. The majority $(72.1 \%)$ of the recorded GlyT2-tdTomato neurons received primary inputs from A $\beta$ fibers.

Conclusion: The present study indicated that spinal GlyT2-positive glycinergic neurons mainly received primary afferent A $\beta$ fiber inputs; the GlyT2-P2A-iCre and GlyT2-tdTomato mice provided a useful animal model to further investigate the function of the $\mathrm{GlyT}^{+}$$\mathrm{PKC} \gamma^{+}$feedforward inhibitory circuit in both physiological and pathological conditions.

Keywords: glycinergic neurons, spinal cord, GlyT2, A $\beta$ fiber, feed-forward inhibitory circuitry

\section{Introduction}

Dorsal spinal cord containing abundant inhibitory and excitatory interneurons is an imperial site for integrating diverse sensory information. ${ }^{1}$ Glycinergic interneurons are one type of inhibitory interneurons in the spinal cord using glycine as their
Correspondence: Yan Lu; Qun Wang

Department of Pain Medicine, Xijing Hospital, Fourth Military Medical University, 127 West Changle Road, Xi'an, 710032, People's Republic of China Tel +86 I34 88I5 6067; +86 I399I29 2III3 Fax +862984771262

Email13488I56067@I63.com; wqfmmu77@I63.com
Journal of Pain Research 2021:14 907-921

DovePres: in $\square$

http:l/doi.org 10.2147 IJPR 5296940 
major neurotransmitters and are thought to be involved in postsynaptic inhibition. ${ }^{2}$ In accordance with this mechanism, numerous behavioral and physiological studies have verified the primary inhibitory function of glycinergic neurons in gating multiple sensory modalities. For example, modulation of spinal glycinergic neurons by genetic or pharmacological methods significantly influenced pain- or itch-related behaviors. ${ }^{3}$ Simultaneously, the altered sensory transmission due to the dysfunction of inhibitory interneurons can also be reversed by compensating glycine-related inhibition. ${ }^{4}$ Primary myelinated $\mathrm{A} \beta$ fibers innervating spinal deeper layers from lamina IIi to IV mainly respond to non-noxious stimulation, while myelinated $\mathrm{A} \delta$ fibers and unmyelinated $\mathrm{C}$ fibers terminating in spinal lamina I and II transmit noxious information. ${ }^{5-7}$

Glycine transporter 2, one isoform of glycine transporter expressed on nerve terminals, is a credible neural marker for identifying glycinergic axons in the central nervous system. ${ }^{8}$ However, this isoform cannot reach detectable levels in cell bodies which make it difficult to identify using immunohistochemistry methods with antibodies. ' Zeilhofer's lab constructed the GlyT2-Cre and GlyT2-GFP mice using the BAC transgenic strategy which marked spinal glycinergic neurons and characterized the morphological and electrophysiological properties of spinal glycinergic neurons. ${ }^{9}$ They furtherly demonstrated that dorsal horn glycinergic neurons function as critical elements of a spinal gate for pain and itch. ${ }^{3}$

By using the Prkcg-P2A-tdTomato mice, we have recently documented that spinal $\mathrm{PKC} \gamma^{+}$neurons receive the feedforward inhibition mediated by $\mathrm{A} \beta$ inputs. $^{10,11}$ Mechanical allodynia was gated by the convergent inputs which regulate the function of $\mathrm{PKC}^{+}$neurons. We further confirmed that the feedforward control on $\mathrm{PKC} \gamma^{+}$neurons was predominantly glycinergic. Previous studies have demonstrated the importance of glycinergic inhibition in processing mechanosensory input in normal and neuropathic pain states. ${ }^{11-15}$ Although these studies indicated that the spinal glycinergic interneurons acted as the key part of allodynia gate, an electrophysiological or dynamic exploration of the synaptic inputs from primary afferent fibers to spinal glycinergic interneurons is largely absent. Therefore, the purpose of the present study was to investigate the synaptic transmission between spinal glycinergic interneurons and primary afferents using a genetic labeled animal model.

In the current work, we developed GlyT2-P2A-iCre knock-in mice using the clustered regularly interspaced short palindromic repeats-associated nuclease 9 (CRISP/ Cas9) technology. The GlyT2-iCre-tdTomato mice were then generated by crossing the GlyT2-P2A-iCre mice with fluorescent reporter mice. Using patch-clamp whole-cell recordings, we analyzed the dynamic synaptic inputs to glycinergic neurons in the GlyT2-iCre-tdTomato mice. We found that the majority $(72.1 \%)$ of the recorded GlyT2 positive glycinergic neurons received primary inputs from $\mathrm{A} \beta$ fibers. The present study provided a useful animal model to investigate the concrete functions of the $\mathrm{GlyT}^{+}-\mathrm{PKC}^{+}$ feedforward inhibitory circuit in the spinal dorsal horn.

\section{Materials and Methods}

\section{Animals}

C57BL/6 and Kunming mice for establishing the GlyT2-P2A -iCre mice were purchased from the Beijing Vital River Laboratory (China). Ai9 Rosa26CAG-loxP-STOP-loxPtdTomato and Rosa26flox-mTRed-Stop-flox-mGFP $(\mathrm{mTmG})$ mice were introduced from the Jackson Laboratories. Male GlyT2-iCre-tdTomato mice (4-5 weeks old) were used for electrophysiological experiments. Animals were fed at $22-24^{\circ} \mathrm{C}$ (room temperature) and housed with a $12 \mathrm{~h} / 12 \mathrm{~h}$ day/night cycle. Water and food were available for the mice ad libitum. The experimental procedures carried on animals were approved and reviewed by the Ethical Committee of the Fourth Military Medical University (protocol number: IACUC-20180606). All animal experiments were conducted according to the Guidelines of NIH for the welfare of the laboratory animals.

\section{GlyT2-P2A-tdTomato Mice Generation Design and Construction of CRISPR Small Guide RNAs (CRISPR/sgRNAs)}

GlyT2-P2A-iCre mice were generated by the CRISP/Cas9 technology. ${ }^{16,17}$ Based on the design principle of sgRNA, a total of 11 sgRNAs were designed in the target region. P2A-iCre cassette was fused into the last codon before the GlyT2 gene. The UCA kit was applied to screen CRISPR sgRNA for on-target activity. Random integrations were minimized by applying a circular donor vector. The donor plasmid containing a P2A sequences and an improved Cre recombinase (iCre) gene were flanked by $1.3 \mathrm{~kb}$ homolog arms. In addition, the donor vector was prepared using a plasmid DNA kit which was endotoxin-free. The acquisition to add the $\mathrm{T} 7$ promoter sequence to the sgRNA and Cas9 templates were performed through PCR amplification. T7-sgRNA PCR and T7-Cas9 products were then gel 
purified and utilized as templates for transcription in vitro with the mMESSAGE mMACHINE $^{\circledR}$ kit and MEGAshortscript T7 kit (Ambion, USA), respectively. Both the sgRNA and Cas9 mRNA were purified by utilizing MEGAclear kit and then eluted with water which was free of RNase.

\section{Microinjection}

The strains of KM mouse and C57BL/6 female mice were used as pseudopregnant foster mothers and embryo donors, respectively. At the one-cell stage, donor vector, Cas9 mRNA and sgRNAs of different concentrations were mixed and subsequently co-injected into the cytoplasm of fertilized eggs. After that, the oviducts were transferred by surviving zygotes of KM pseudopregnant females.

\section{Genotyping}

Genomic DNA from the tail of 7-day mice (F0) was extracted using alkaline lysis method. The genotype for GlyT2-iCre knock-in allele was verified by PCR technology and direct sequencing. Two pairs of primers were designed (Takara Bio Inc., USA) which EGE-YQL-014WT-F and EGE-YQL-014-WT-R primers were used to detect the WT alleles, and EGE-YQL-014-WT-F and EGE-YQL-014-Mut-R were used to identify the mutant alleles.

\section{Southern Blot Analysis}

For Southern blotting, briefly, genomic DNA which was extracted from mouse tails was firstly digested by AseI or BglII (New England BioLabs, USA) and added into agarose gel (1\%) for electrophoresis. After that, the DNA gel was then shifted to nylon membranes (Hybond $\mathrm{N}+$; Amersham International plc, United Kingdom) which was positively charged. By using DIG Easy Hyb Granules (Roche, USA) which contains DIG labeling probe, the nylon membrane was hybridized overnight at $42^{\circ} \mathrm{C}$. In order to acquire probe labeling, $3^{\prime}$ internally and externally DIG-labeled probes were performed by PCR which incorporates DIG-11-dUTP and utilizes Taq DNA polymerase according to the instructions of the manufacturer. The DIG Luminescent Detection kit (Roche, USA) was applied for the detection of hybridization signals.

\section{Genetic Strategy for GlyT2-P2A-iCre Mice}

As shown in the diagram of constructed GlyT2-P2A-iCre (Figure 1A), the P2A-iCre sequence was inserted into the last codon of GlyT2 gene using the CRISPR/Cas9 technique. 3 'external probe (WT: $8.1 \mathrm{~kb}$; KI allele: $5.5 \mathrm{~kb}$ ) and the internal probe (WT: $6.4 \mathrm{~kb}$; KI allele: $4.7 \mathrm{~kb}$ ) were used in southern blot to identify four correctly targeted F1 pups (Figure 1B). Two pairs of primers (WT-F/WT-R and WTF/Mut-R) used in the polymerase chain reaction (PCR) were conducted to detect the genotypes of mice (Figure 1C).

\section{Immunohistochemistry}

Male GlyT2-iCre-tdTomato mice (4-8 weeks) were anesthetized deeply by injecting pentobarbital sodium $(50 \mathrm{mg} / \mathrm{kg}$ ) intraperitoneally. The mice were immediately perfused in order with the saline and ice-cold paraformaldehyde (PFA). Then, the spinal cord tissue was extracted and post-fixed in the PFA (4\%), followed by dehydrating with $20 \%$ and $30 \%$ sucrose for $24 \mathrm{~h}$, respectively, at $4^{\circ} \mathrm{C}$. Then, the spinal cord was cut into sections $(25 \mu \mathrm{m})$ by Cryostat Microtome (Leica, Germany). After being washed in phosphate buffer saline (PBS), they were blocked in donkey serum (5\%) for $2 \mathrm{~h}$ at room temperature (RT) and subsequently incubated in $2.5 \%$ donkey serum-containing primary antibodies: anti-Pax2 (rabbit, 1:500; Abcam, USA), anti-Glycine (rabbit, 1:200; Abcam, USA), anti-SP (guinea pig, 1:500; Abcam, USA), anti-CGRP (goat, 1:500; Abcam, USA), anti-PKC $\gamma$ (rabbit, 1:400; Santa Cruz, USA) for $12-18 \mathrm{~h}$ at $4^{\circ} \mathrm{C}$. After that, they were incubated with secondary antibodies which included donkey anti-rabbit IgG with Alexa Fluor 488 (1:500; Molecular Probes, USA), donkey anti-guinea pig IgG conjugated with Alexa Fluor 488 (1:500; Molecular Probes, USA), donkey antigoat IgG with Alexa Fluor 488 (1:500; Molecular Probes, USA), respectively, for $3 \mathrm{~h}$ at RT. Besides, some of the fluorescent spinal cord slices were directly incubated with the IB4 (1:200; Vector Laboratories, USA).

\section{In situ Hybridization}

Methods for in situ hybridization (ISH) which were related to vesicular glutamate transporter 2 (Vlgut2) have been described in previous articles. ${ }^{10,18,19}$ Briefly, sections from three GlyT2-tdTomato male mice were applied in this procedure. For the acquisition of tdTomato fluorescent images, slices were captured under a confocal scanning microscope installed with laser (Olympus FV1200, Japan). In situ signals of Vglut2 were obtained under transluminescent light and pseudo-green fluorescent color. The overlay between red fluorescence positive images and Vglut2 (green) images was conducted by Photoshop software (USA) 
A

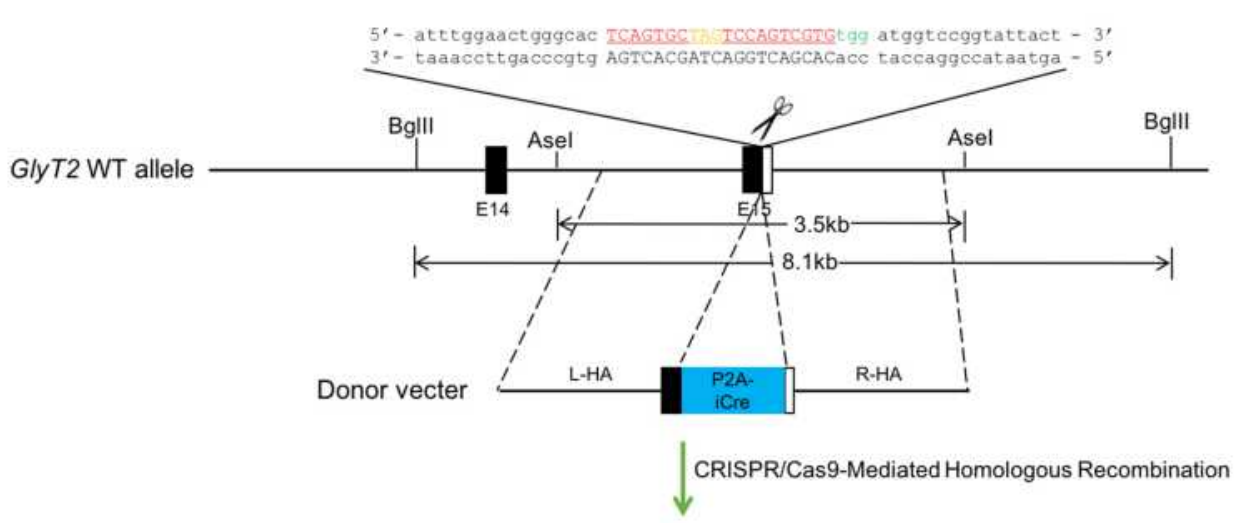

GlyT2 KI allele

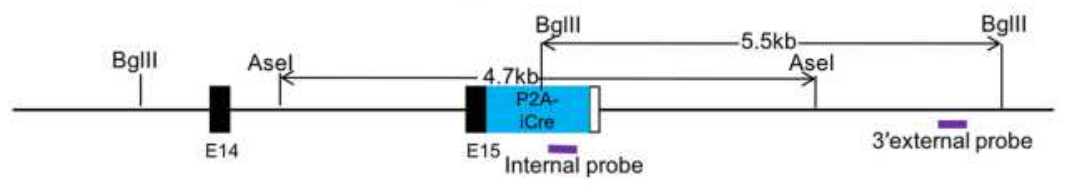

B
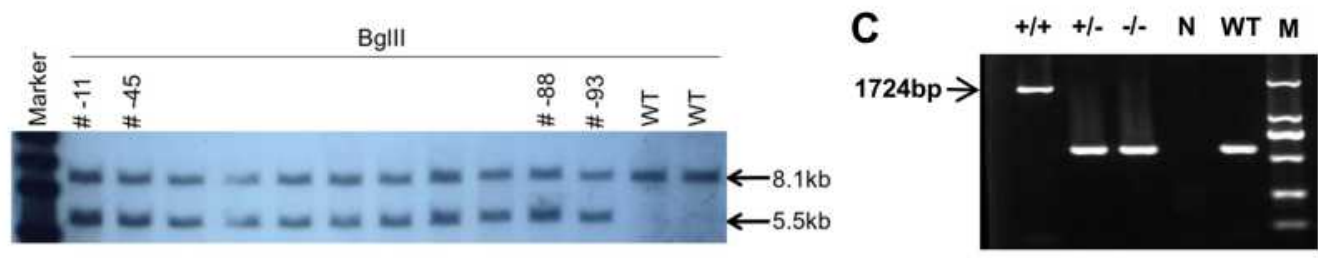

3'external probe

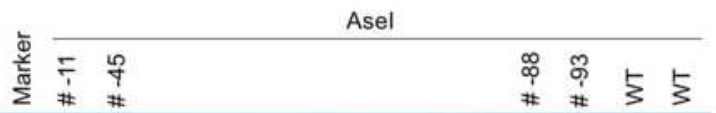

Internal probe
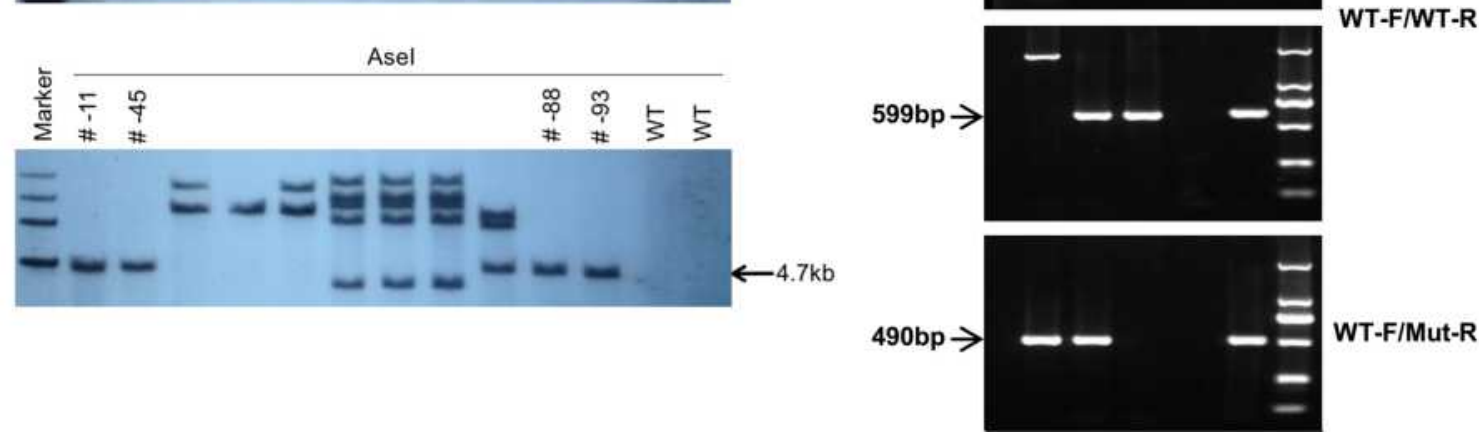

Figure I Generation of GlyT2-p2A-iCre mice.

Notes: (A) Strategy of P2A-iCre knock-in (KI) allele. The guide RNA sequence was marked with red. The protospacer-adjacent motif (PAM) sequence was labeled with green. The stop codon of P2A-iCre was labeled with orange. The purple boxes depicted the probe applied for Southern blotting. (B) Three correctly targeted FI pups were identified by southern blot analysis using the $3^{\prime}$ external probe (WT: $8.1 \mathrm{~kb}$; KI allele: $5.5 \mathrm{~kb}$ ) and the internal probe (KI allele: $\left.4.7 \mathrm{~kb}\right)$. (C) PCR analysis of P2A-iCre from KI/ WT mice. The number on the left shows three pairs of primers. The product size of each pair of primers was indicated by arrows. $M=$ marker, $N=$ negative control, $\pm=$ heterozygote, $+/+=$ homozygote.

\section{Preparation of the Sagittal Spinal Slices Attached with Dorsal Roots}

Parasagittal spinal cord slices were prepared from male GlyT2-iCre-tdTomato mice. In brief, mice were intraperitoneally injected with pentobarbital sodium $(50 \mathrm{mg} / \mathrm{kg})$ and then the spinal cord was rapidly extracted. Subsequently, the lumbar part of the whole tissue with dorsal roots was carefully removed and was fixed on the platform made of agar. Parasagittal spinal slices (400-600 $\mu \mathrm{m})$ were cut by the vibrating microtome in icy sucrose artificial cerebrospinal fluid (ACSF) composed by (in $\mathrm{mM}$ ) sucrose $75, \mathrm{NaH} 2 \mathrm{PO} 41.25, \mathrm{MgCl} 21.2, \mathrm{NaCl} 80$, $\mathrm{KCl} 2.5, \mathrm{CaCl} 22.5, \mathrm{NaHCO} 325$, sodium pyruvate 3.0 and ascorbate 1.3 (osmolality at $310-320 \mathrm{mOsm}$ and $\mathrm{pH}$ at 7.4), and were then incubated immediately in ACSF (in $\mathrm{mM}$ ) $\mathrm{KCl} 2.5, \mathrm{NaCl} \mathrm{125,} \mathrm{CaCl} 2$ 2, $\mathrm{NaHCO} 326$, $\mathrm{NaH} 2 \mathrm{PO} 41.25$, D-glucose $25, \mathrm{MgCl} 21$, sodium pyruvate 3.0 and sodium ascorbate 1.3 (osmolality at $310-320$ mOsm and $\mathrm{pH}$ at 7.2 ) pre-oxygenated with $95 \% \mathrm{O} 2$ and $5 \% \mathrm{CO} 2$ at $\mathrm{RT}$ for $1 \mathrm{~h}$. 


\section{Whole-Cell Recording and Dorsal Root}

\section{Stimulation}

According to the protocol utilized in our previous study, ${ }^{6,710,20}$ spinal cord slice was placed in the bath filled with circulated artificial cerebrospinal fluid. The GlyT2tdTomato neurons were observed by the upright microscope which was installed with infrared differential interference contrast (IR-DIC), together with green luminescence. Filled

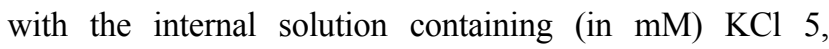
K-gluconate 130, phosphocreatine 10, Li-GTP 0.3, MgATP 4, and HEPES 10 (osmolality at $300 \mathrm{mOsm}$ and $\mathrm{pH}$ at 7.3), the recording electrode with resistance maintained at $5-10 \Omega \mathrm{M}$ was used to record signals from patched cells.

Recordings of the whole-cell patch were performed on the GlyT2-tdTomato neurons randomly selected in the spinal dorsal horn. The resting membrane potential (RMP) was identified initially after the establishment of whole-cell configuration in $\mathrm{I}=0$ model. In I-Clamp mode, the action potential (AP) firing was confirmed through injecting step depolarizing pulses (1 $\mathrm{s}$ duration) with 25 pA step from the holding potential $(-60 \mathrm{mV})$. The data are acquired by the pClamp 10.0 software, Digidata 1440 A (Molecular Devices) and multiClamp 200B amplifier. Response signals were filtered at $5 \mathrm{kHz}$ by low-pass.

The procedures for dorsal root stimulation have been reported previously. ${ }^{6,710,20} 0.1$ to $0.5 \mathrm{~ms}$ graded pulses were applied by suction electrodes to stimulate the dorsal roots. The conduction velocities (CVs) of afferent fibers were calculated by the combination of latency with the conduction distance of the recorded response. Evoked excitatory and inhibitory postsynaptic potentials were acquired by applying graded intensity which could recruit $A \beta, A \delta$ and $C$ fibers. Response threshold and CVs were combined to classify synaptic responses from primary afferent fibers (A $\beta, A \delta$ or $C)$. Evoked EPSPs with the absence of failures and constant latency in repetitive trials (20 $\mathrm{Hz}$ or $1 \mathrm{~Hz}$ ) were judged to be mediated by monosynaptic A or C fibers. ${ }^{6,7}$ The CVs and response thresholds for the above fibers were confirmed according to our experimental conditions. Dorsal roots were stimulated orthodromically $(0.5 \mathrm{~ms}$ for $\mathrm{C}$ fiber and $0.1 \mathrm{~ms}$ for $\mathrm{A}$ fiber). AP responses were acquired at its central end extracellularly. The criteria of intensities for identifying different types of fibers were 0.1 to $0.3 \mathrm{~V}$ $(\mathrm{A} \beta), 0.4$ to $1.0 \mathrm{~V}(\mathrm{~A} \delta)$, and 1.4 to $6 \mathrm{~V}(\mathrm{C})$, which was accordant to our previous reports. ${ }^{8}$

To label the cells during whole-cell recording, an internal solution containing biocytin $(0.5 \%)$ was essential. Spinal cord slices used for the electrophysiological experiments were post-fixed with 4\% PFA and immersed with sucrose $(20 \%$ and $30 \%$ ) gradiently. After that, slices were washed in the Tris-Triton buffer and subsequently blocked with normal goat serum (4\%). Then, the slices were immerged in a solution containing 1:500 streptavidin conjugated with Fluorescein green (Vector Laboratories, SA-5001). Confocal images were then obtained by fluorescent microscopy (Olympus FV1200, Japan).

\section{Determination of Morphological Characteristics of GlyT2-tdTomato Neuron}

The classification criteria for morphological features of GlyT2 neurons were in accordance with our previous study. ${ }^{10}$ Central cells belong to the neuron types which extended their dendrites mainly in the rostro-caudal direction with their dendrite length extended less than $200 \mu \mathrm{m}$. Islet cells, similar to the central cells, elongated their dendrites longer than $450 \mu \mathrm{m}$ and even reach $600 \mu \mathrm{m}$. Both of these neurons exhibited limited dendrites extension in the dorsal-ventral plane.

\section{Data Analysis}

Categorical variables are expressed as frequency (mean \pm SEM \%). There were no missing data in the present study. Graph figures were made using the Prism GraphPad8.0 software (GraphPad Software Inc., USA).

\section{Results \\ Glycinergic Neurons Were Labeled Successfully in GlyT2-tdTomato Mice}

To specifically mark GlyT2 neurons with fluorescence, we crossed the GlyT2-iCre mice with Rosa26CAGloxP-STOP-loxP-tdTomato mice to get the GlyT2-iCretdTomato mice (Figure 2). By analyzing colocalization of GlyT2-tdTomato and GlyT2mRNA probe through in situ hybridization methods, we found that 89.8 $\pm 1.0 \%$ tdTomato neurons overlay with the GlyT2mRNA, and $93.1 \pm 1.1 \%$ GlyT2 mRNA neurons colocalized with tdTomato (Figure 3A). In order to confirm whether neurons marked by red fluorescence in $\mathrm{GlyT}^{+}$mice were inhibitory, the colocalization between tdTomato positive neurons and Vglut2 (the marker of excitatory neurons) positive neurons was examined. ${ }^{21,22}$ We identified that only $6.8 \pm 1.8 \%$ of tdTomato + neurons express VGLUT2 (Figure 3B). To furtherly testify that the tdTomato labeled neurons in GlyT2-tdTomato mice were mainly glycinergic 


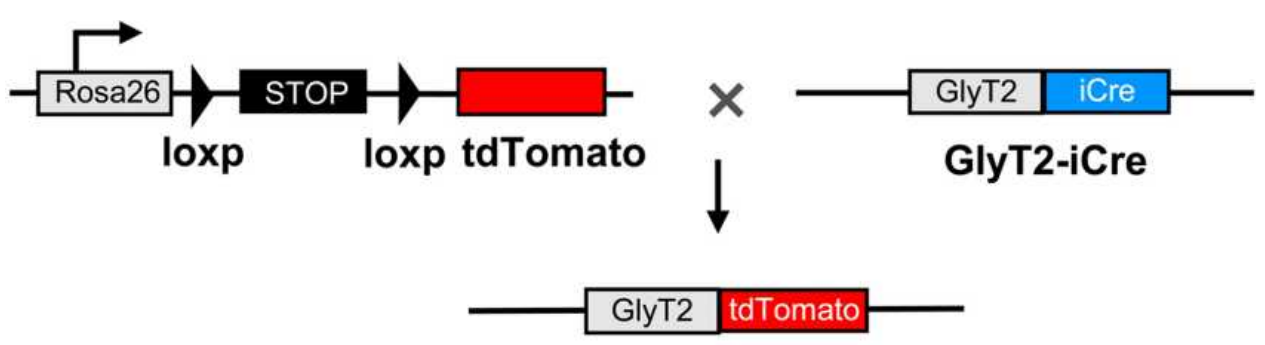

\section{GlyT2-tdTomato}

Figure 2 Schematic description of GlyT2-tdTomato mice generation.

Note: GlyT2-tdTomato mice were generated by crossing the GlyT2-iCre mice with Rosa26CAG-loxP-STOP-loxP-tdTomato mice.
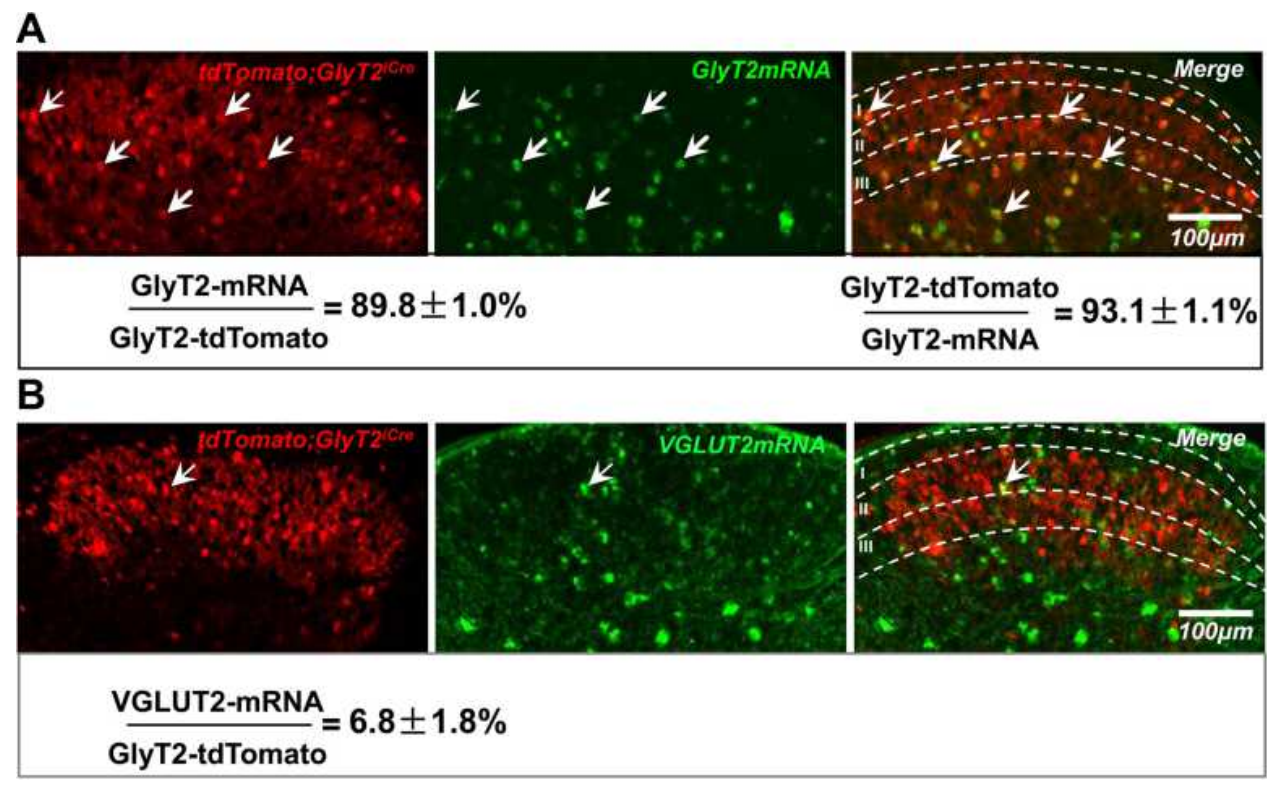

Figure 3 GlyT2-tdTomato colocalized with GlyT2 mRNA in spinal dorsal horn.

Notes: In situ hybridization images depicting tdTomato positive neurons (red) with GlyT2 mRNA (A) and Vglut2 mRNA (B) marked by green probe. Arrows indicated GlyT2-tdTomato neurons co-expressed with GlyT2 mRNA (A) or Vglut2 mRNA (B). Percentage of double-labeled neurons was shown under the images. $\mathrm{n}=3$ mice; 3 sections of each mouse. Data were shown as mean \pm SEM.

inhibitory neurons, we performed immunohistochemistry on transverse spinal slices from GlyT2-tdTomato mice by applying anti-Pax2 (transcription factor expressed by the inhibitory neurons of spinal dorsal horn) antibody and glycine antibody. The results showed that $78.7 \pm 3.8 \%$ GlyT2-tdTomato neurons were Pax2 positive (Figure $4 \mathrm{~A}$ ), and $77.4 \pm 5.4 \%$ GlyT2tdTomato neurons were glycine positive (Figure 4B). Simultaneously, GlyT2-tdTomato neurons constitute $65.6 \pm 1.1 \%$ neurons marked by anti-Pax 2 antibody and $60.9 \pm 2.2 \%$ neurons marked by anti-glycine antibody in lamina I-IV (Figure 4A and B). The above results indicated that tdTomato convincingly marked most glycinergic interneurons in the spinal dorsal horn.

\section{GlyT2-tdTomato Neurons Were Mainly Located in Lamina Ili to IV of Spinal Dorsal Horn}

Next, we identified the laminar distribution of the GlyT2tdTomato neurons by observing colocalization with different laminar makers in the spinal cord. Substance P, binding to the NK1 receptor mainly expressed on the ascending projection neurons, distributed in the lamina $\mathrm{I}^{23} \mathrm{We}$ observed that only a few GlyT2-tdTomato neurons were located at the lamina I (Figure 5A). The nociceptors of $\mathrm{C}$-fiber are subdivided into $\mathrm{CGRP}^{+}$peptidergic and lectin $\mathrm{IB}^{+}{ }^{+}$non-peptidergic neurons, which mainly target outer lamina II (lamina IIo) and dorsal part of inner lamina II 


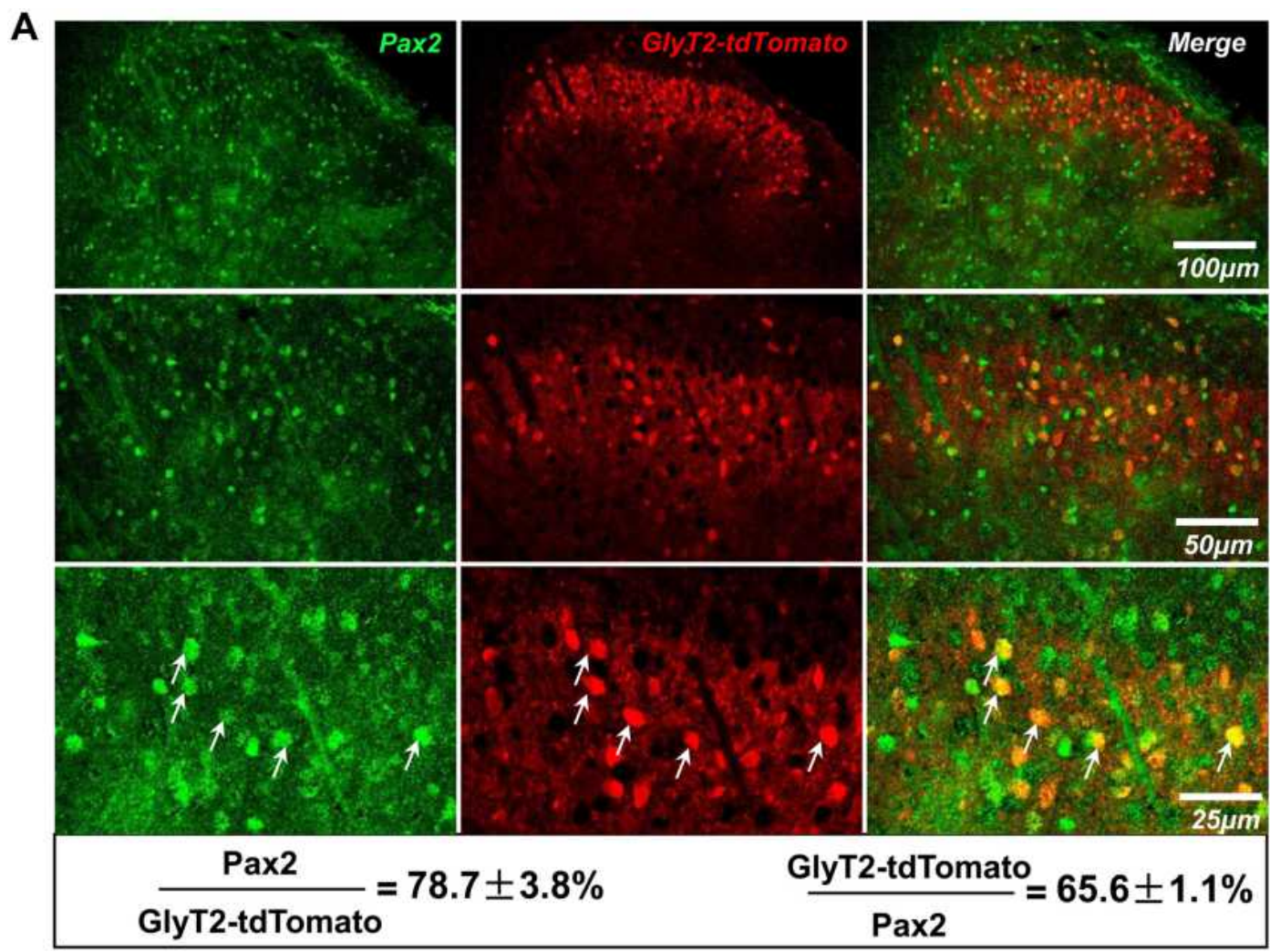

B

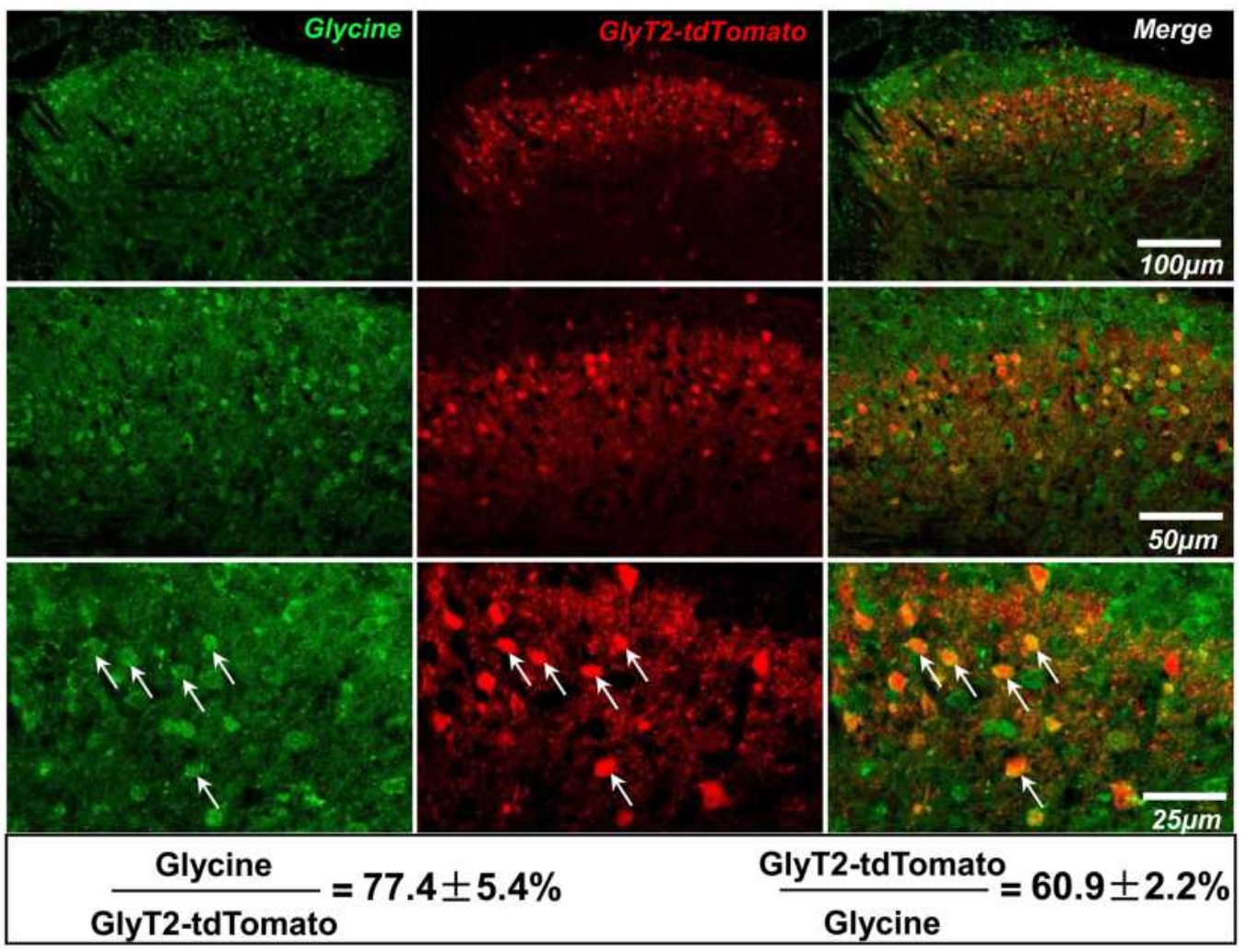

Figure 4 GlyT2-tdTomato colocalized with immunoreactivity of Pax2 and glycine in spinal dorsal horn.

Notes: Immunohistochemical images depicting tdTomato positive neurons (red) with Pax2 (A) and glycine (B) marked by green fluorescence. Arrows indicated GlyT2tdTomato neurons co-expressed with Pax2 (A) or glycine (B). Percentage of double-labeled neurons was shown under the images. $n=3$ mice; 3 sections of each mouse. Data were shown as mean \pm SEM. 


\section{A}
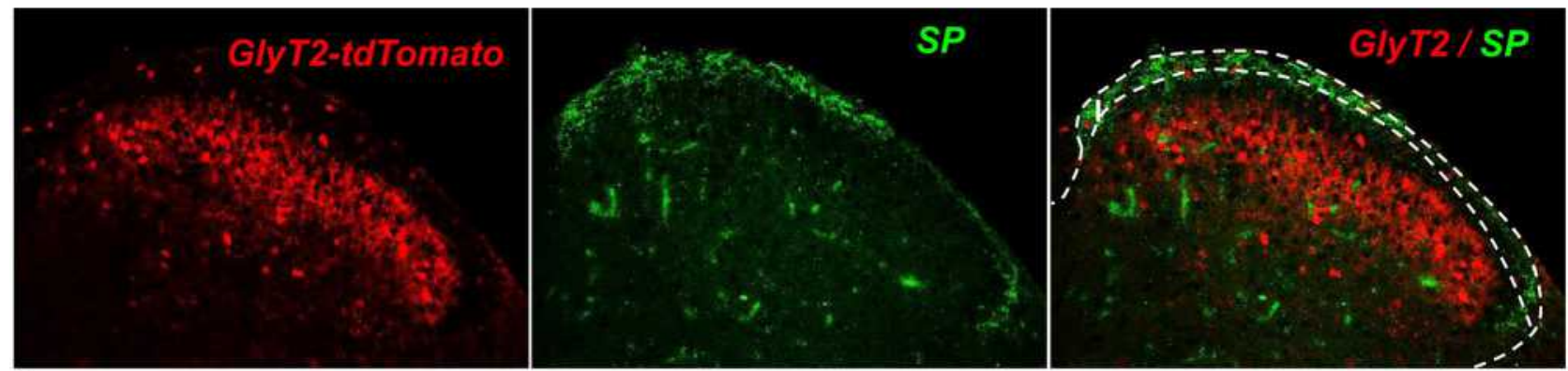

B
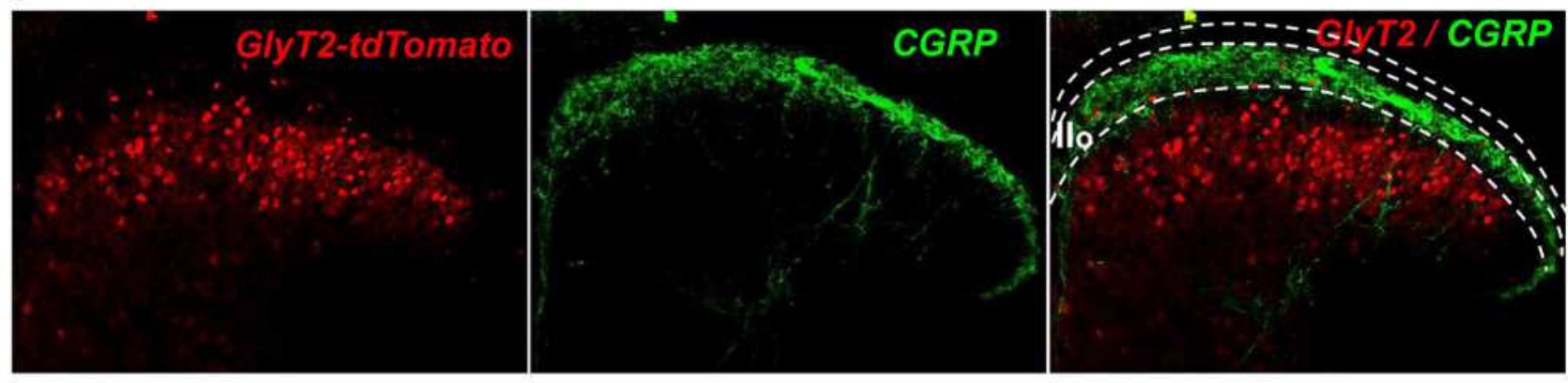

C
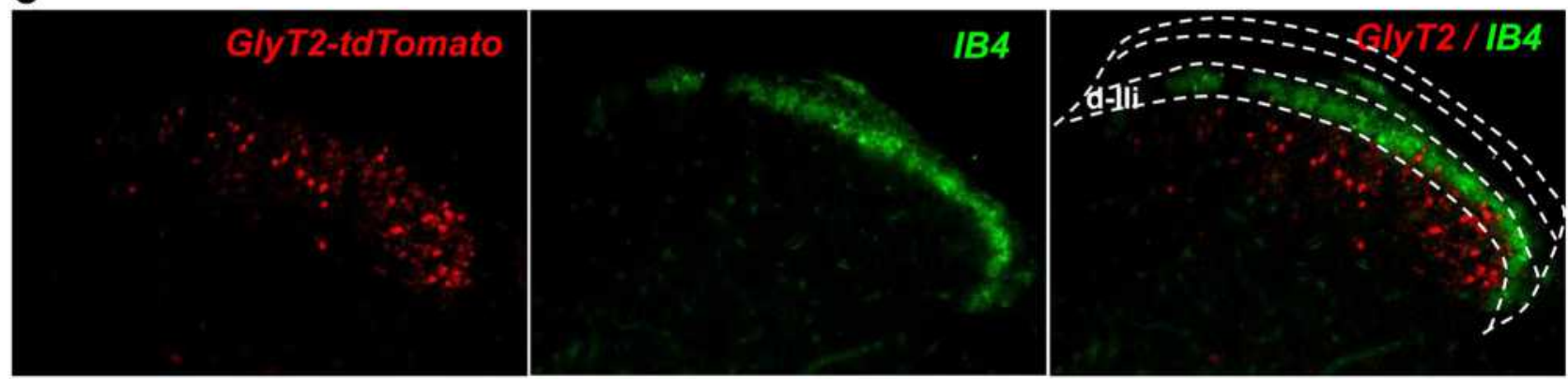

D
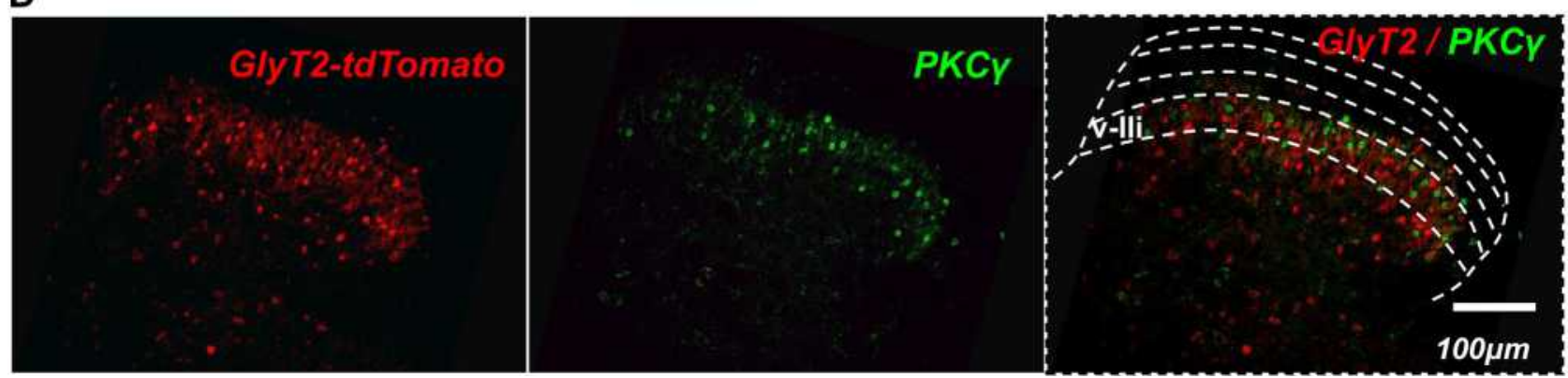

Figure 5 GlyT2-tdTomato neurons were mainly located in lamina Ili to IV of spinal dorsal horn.

Notes: GlyT2-tdTomato positive neurons were rarely located in lamina I labeled with SP (A), lamina llo labeled with CGRP (B) and dorsal part of lamina Ili labeled with IB4 (C). Large amount of GlyT2-tdTomato positive neurons were located in the ventral part of lamina Ili labeled with PKC $\gamma$ (D) and lamina III. Scattered GlyT2-tdTomato positive neurons were also seen in lamina IV (D).

(lamina IIi-d), respectively. The ventral part of inner lamina II (lamina IIi-v) is mainly innervated by the $A \beta$ fibers and low threshold $\mathrm{C}$ fibers and always defined by the protein kinase $\mathrm{C} \gamma(\mathrm{PKC} \gamma)$. We found that there are still a few GlyT2-tdTomato neurons scatter within the lamina
IIo and lamina IIi-d. GlyT2-tdTomato neurons were mainly distributed in the deeper layers from lamina IIi to lamina IV (Figure 5B-D). The laminar distribution of the GlyT2-tdTomato neurons is consistent with GlyT2-EGFP mice developed by Zeilhofer's group. ${ }^{9}$ 


\section{GlyT2-tdTomato Neurons Mainly Showed Tonic Firing Pattern and Central Morphology}

Since the firing pattern of recorded neurons could be used to clarify neuron subclass in the spinal cord, ${ }^{6}$ we monitored the pattern of action potentials elicited with $1 \mathrm{~s}$ depolarized square stimulation. The discharge patterns of GlyT2tdTomato neurons were identified in line with previous research. Tonic firing is the one action potential that appears regularly and even shows adaptability during the stimulation. The action potentials that only appear in the early stage of current injection were categorized into initial bursting firing. Delayed firing type is identified as neurons whose action potential discharge after the first $100 \mathrm{~ms}$ of current injection and the delay of which will be correspondingly shortened but still shorter than $100 \mathrm{~ms}$ with the increase of current. We found that $80 \%$ (66 of 83 ), 19\% (6 of 83 ) and 1\% (4 of 83)
GlyT2-tdTomato neurons showed tonic, initial bursting and delayed discharge pattern, respectively (Figure 6A-B).

Spinal inhibitory interneurons mainly showed central or islet types compared with excitatory neurons which displayed radical morphology. ${ }^{24}$ Based on our previous classification criteria, 78\% (7 of 9) of recorded cells showed central morphology (Figure 7A and C). The rest of the recoded neurons $(22 \%, 2$ of 9$)$ were characterized as Islet type (Figure 7B and $\mathrm{C}$ ). Taken together, our results depicted that the physiological and morphological properties of spinal GlyT2-tdTomato neurons were consistent with features of spinal inhibitory interneurons.

\section{GlyT2-tdTomato Neurons Mainly Receive Monosynaptic Inputs from A $\beta$ Fibers}

As the modulation of sensory information mainly depends on neural circuits composed of primary afferent fibers and

\section{A Tonic}
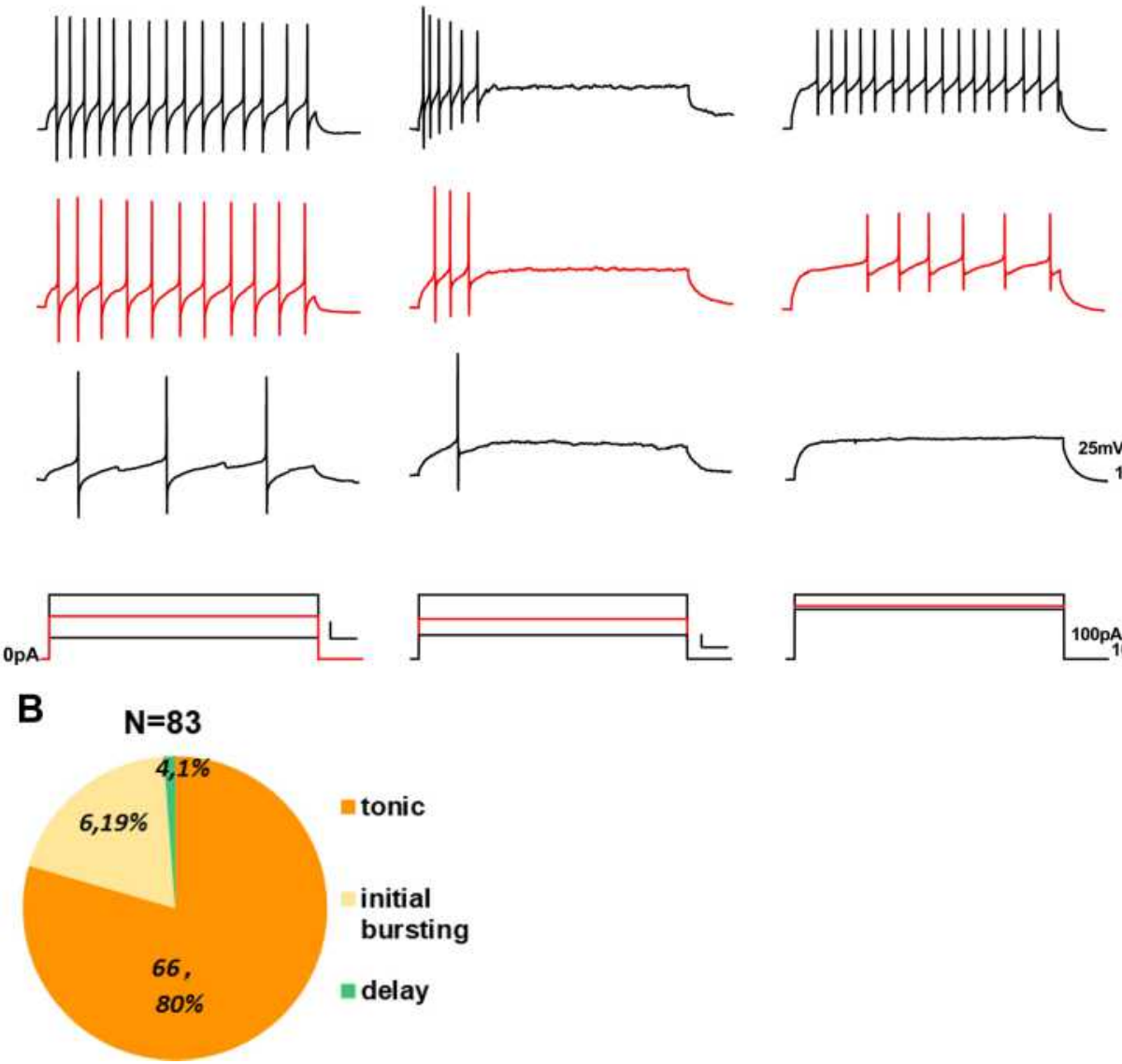

Figure 6 Firing patterns of GlyT2-tdTomato neurons in spinal dorsal horn.

Notes: (A) Representative examples of tonic, initial bursting and delayed firing patterns recorded from GlyT2-tdTomato neurons by injecting different intensities of depolarizing current. (B) Proportion of different firing patterns acquired from GlyT2-tdTomato neurons. 
A

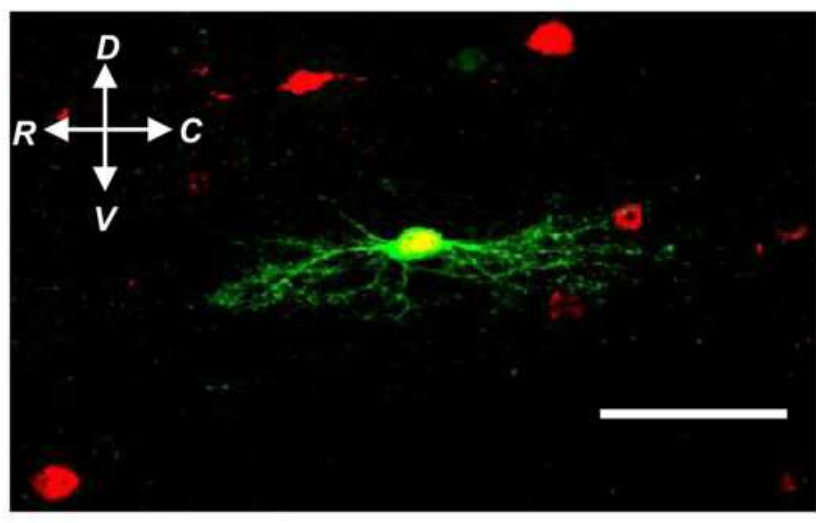

B

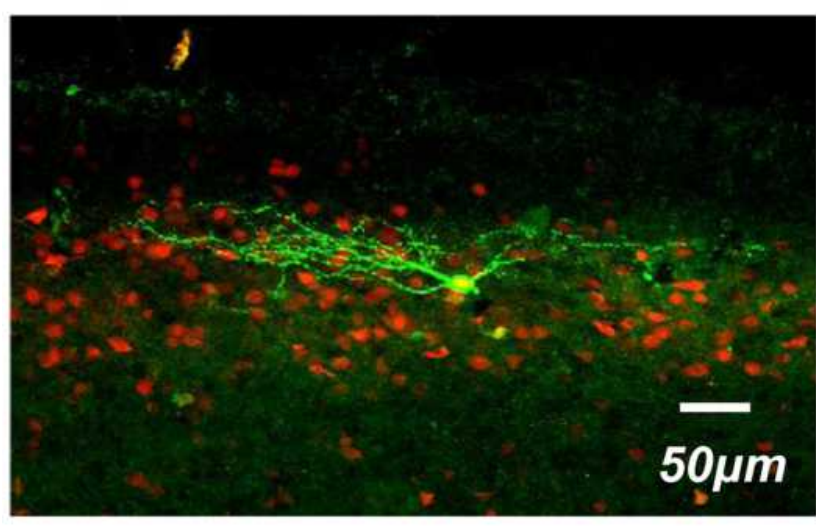

C

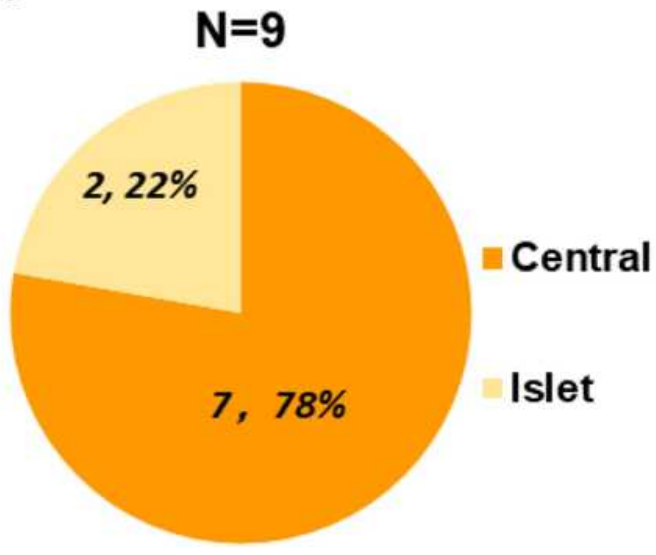

Figure 7 Morphologic features of GlyT2-tdTomato neurons in parasagittal spinal slice.

Notes: Representative examples of GlyT2-tdTomato neurons (red) filled with biocytin (green) match with central (A) and islet (B) properties. (C) Proportions of the cells with different morphological features.

numerous interneurons, a comprehensive mastery of synaptic transmission to GlyT2-tdTomato neurons from the periphery will better understand its role in the modulation of sensory inputs. In order to address the concrete inputs to glycinergic neurons, we randomly selected and recorded 61 GlyT2-tdTomato neurons in lamina IIi and III of the spinal dorsal horn where a large number of glycinergic neurons located. Stimulation of dorsal root was applied to elicit synaptic responses in recoded GlyT2tdTomato neurons. The results showed that $72.1 \%$ (44 of 61) of the GlyT2-tdTomato neurons were innervated by $\mathrm{A} \beta$ fibers, of which, 49.2\% (30 of 61) neurons were evoked monosynaptic excitatory postsynaptic potentials (EPSPs) (Figure 8A), while 9.8\% (6 of 61) neurons were evoked polysynaptic EPSPs (Figure $8 \mathrm{~B}$ ). In addition, dorsal root stimulation also evoked $\mathrm{A} \beta$ fiber mediated mixed excitatory and inhibitory synaptic responses in $6.6 \%$ (4 of 61, EPSP-IPSP, Figure 8C), 4.9\% (3 of 61, IPSP-EPSP, Figure 8D) and 1.6\% (1 of 61, IPSP only, Figure 8E) GlyT2-tdTomato neurons. We also found that 19.7\% (12 of 61) of the GlyT2-tdTomato neurons were dominated by A $\delta$ fibers, of which, 3.3\% (2 of 61) of the neurons were evoked monosynaptic EPSPs (Figure 8F), 9.8\% (6 of 61) of the neurons were evoked polysynaptic EPSPs, and $6.6 \%$ (4 of 61) of the neurons were evoked EPSP-IPSP (Figure 8G). C fiber-mediated monosynaptic EPSPs were detected in $4.9 \%$ (3 of 61 ) of the GlyT2-tdTomato neurons (Figure $8 \mathrm{H}$ ). Lastly, 3.3\% (2 of 61) of the GlyT2-tdTomato neurons were innervated by both $\mathrm{A} \beta$ and $\mathrm{C}$ fibers (Figure 8I). Taken together, the present study indicated that glycinergic neurons in the spinal dorsal horn mainly received excitatory inputs from peripheral $A \beta$ fibers, although $A \delta$ and $\mathrm{C}$ fiber inputs were detected in some glycinergic neurons (Figure 8J).

The correlations between primary afferent types and firing patterns in GlyT2-tdTomato labeled neurons were analyzed. Of the total 44 neurons receiving $\mathrm{A} \beta$ fiber input, $39 / 44$ of cells displayed tonic firing, 4/44 of cells displayed Initial bursting firing and $1 / 44$ of cells displayed delay firing (Table 1 ). Of the total 12 neurons receiving $A \beta$ fiber input, 10/12 of cells displayed tonic firing, 2/12 of cells displayed Initial bursting firing. Three neurons receiving $\mathrm{C}$ fiber input displayed tonic firing (Table 1). We also analyzed the correlations between primary afferent types and morphological features in biocytin labeled GlyT2-tdTomato neurons. 6 of 7 central cells received $A \beta$ fiber input, the rest one central cell received $\mathrm{C}$ fiber input. 2 of 2 islet neurons received $A \beta$ fiber input. From the above results, we can conclude that most of spinal glycinergic neurons are more likely to be tonic central cells receiving $A \beta$ fiber input. 
A

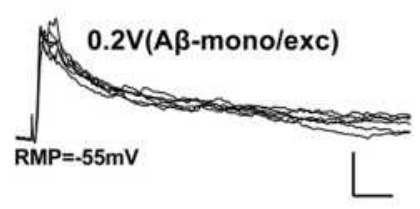

D

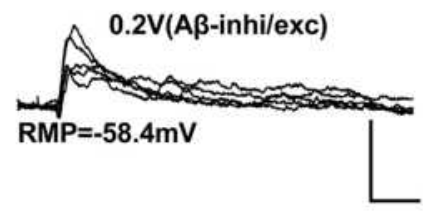

F

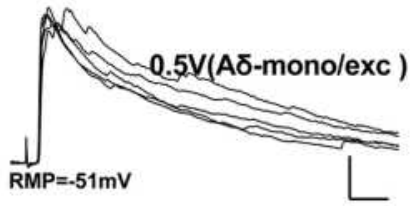

I

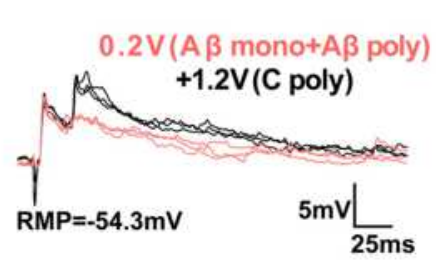

B

E

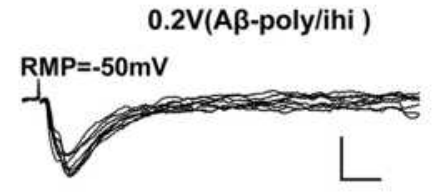

G

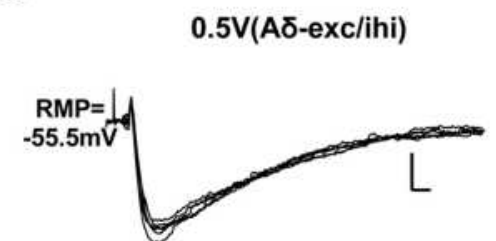

J

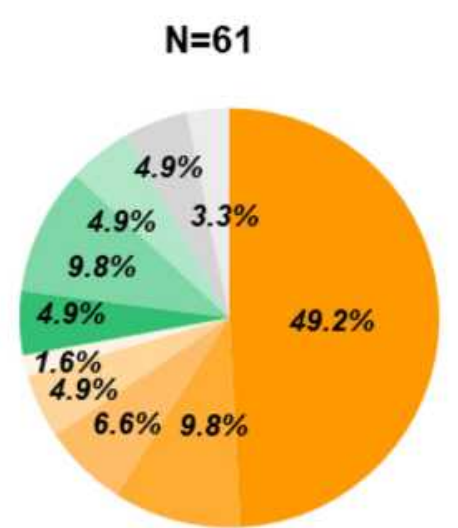

C $0.2 \mathrm{~V}$ (Aß-exc/ihi)

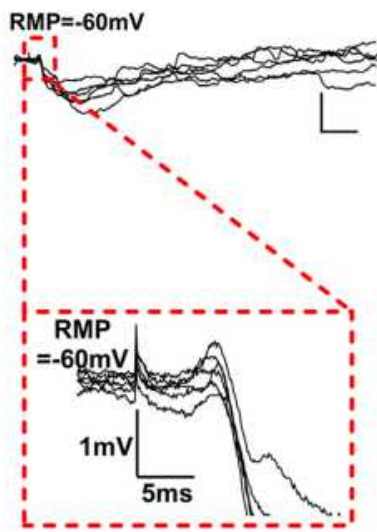

H

$1.2 \mathrm{~V}$ (C-mono+poly/exc)

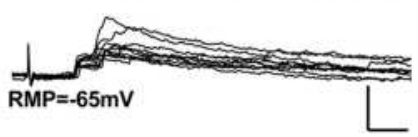

\section{$=\mathrm{A} \beta$-mono/exc}

\section{$=\mathrm{A} \beta$-poly/exc}

A $\beta$-exc/ihi

$A \beta$-ihi/exc

$A \beta$-ihi

$\equiv \mathrm{Ao}-\mathrm{mono} / \mathrm{exc}$

$=A \delta-p o l y / e x c$

Aס-exc/ihi

C-mono+poly/exc

$A \beta+C$-exc

Figure 8 The primary afferents received by GlyT2-tdTomato neurons.

Notes: (A) Monosynaptic eEPSPs evoked by A $\beta$ fiber stimulation. (B) Polysynaptic eEPSPs evoked by A $\beta$ fiber stimulation. (C) eEPSPs-elPSP and (D) elPSP-eEPSPs mediated by $A \beta$ fibers. (E) elPSPs mediated by A $\beta$ fibers. (F) Monosynaptic eEPSPs evoked by A $\delta$ fiber stimulation. (G) eEPSPs-elPSP mediated by A $\delta$ fibers. (H) Mono- and Polysynaptic eEPSPs evoked by $C$ fiber stimulation. (I) eEPSPs mediated by both $A \beta$ and $C$ fibers. (J) Percentage of synaptic inputs to GlyT2-tdTomato neurons from primary $A \delta$, $A \beta$ and $C$ fibers.

Abbreviations: eEPSPs, evoked excitatory postsynaptic potentials; elPSPs, evoked inhibitory postsynaptic potentials; mono, monosynaptic; poly, polysynaptic; exc, excitatory; inh, inhibitory. 
Table I Correlations Between Primary Afferent Types and Firing Patterns in GlyT2-tdTomato Labeled Neurons

\begin{tabular}{|l|l|l|l|l|}
\hline \multirow{2}{*}{$\begin{array}{l}\text { Type of Primary } \\
\text { Afferents }\end{array}$} & \multirow{2}{*}{} & \multicolumn{3}{|c|}{ Firing Patterns } \\
\cline { 3 - 5 } & & Tonic & $\begin{array}{l}\text { Initial } \\
\text { Bursting }\end{array}$ & Delay \\
\hline A $\beta$ fiber & 44 & 39 & 4 & $\mathrm{I}$ \\
A $\delta$ fiber & 12 & 10 & 2 & 0 \\
C fiber & 3 & 3 & 0 & 0 \\
A $\beta+C$ fiber & 2 & I & 0 & I \\
\hline
\end{tabular}

Note: $n$, number of neurons receiving primary afferent.

\section{Discussion}

In the present study, we constructed the GlyT2-P2A-iCre mice using the CRISP/Cas9 technique, and subsequently generated GlyT2-tdTomato mice, which allowed us to record the GlyT2-tdTomato neurons directly. We found that the majority (72.1\%) of the recorded GlyT2-tdTomato neurons received primary inputs from $A \beta$ fibers, $19.7 \%$ of the recorded neurons were innervated by $A \beta$ fibers and only $4.9 \%$ of the recorded neurons were innervated by $\mathrm{C}$ fibers. Only a few neurons received mixed inputs from $A \beta$ and $\mathrm{C}$ fibers. The distribution, firing patterns and morphological characteristics of GlyT2-tdTomato neurons were further illuminated. The present study provides a useful animal model for further investigation of the $\mathrm{GlyT}^{+}-\mathrm{PKC} \gamma^{+}$feedforward inhibitory circuit. $^{10}$

Although GlyT2-Cre mice have been developed by Nathaniel Heintz and Zeilhofer et al using the BAC transgenic technology, ${ }^{3,9,25,26}$ there are some defects in BAC mice line compared with CRISPR/Cas9 mice line. As an example, the number of gene copy of early generations in BAC transgenic mice may not be identical and guaranteed. It is necessary to mate for several generations to obtain stable genetic lines with certain copy number. Also, the expression of Cre gene would increase correspondingly with the obtainment of positive mice with high copy number, but would simultaneously be at the cost of acquiring certain toxicity on the BAC mice. In addition, to avoid the circumstance in which the Cre of BAC transgenic mice locate on the same chromosome when mating with flox or reporter mice, chromosome site of BAC transgenic mice may also be needed for consideration. In our experiment, P2A-iCre was knocked into the C-terminal of the gene in which Cre and native protein could be expressed simultaneously by applying the CRISPR/cas9 technology. Our results showed that iCre gene on the positive mice could reflect the location of GlyT2 expression accurately and the copy number can be determined by simple genotype identification, suggesting that this mice line established by the CRISPRI/Cas9 technique is more specific and efficient. ${ }^{27}$

Consistent with previous research which depicted that glycinergic neurons are mainly located in deep layers of the spinal dorsal horn, ${ }^{28,29}$ our results further demonstrated these cells were abundantly distributed from lamina IIi to lamina IV. In addition, the firing pattern we mainly encountered was tonic which represents large amounts of inhibitory interneurons. ${ }^{30}$ In previous studies, morphology and firing pattern of neurons were often used as criteria for neuron classification. ${ }^{6,7}$ The morphological features (important indicator for classification of neurons in dorsal spinal cord) of recorded cells meet the features of central and islet type which is consistent with the observation of Toshiharu Yasaka et al. ${ }^{24}$

Deep lamina of the dorsal horn mainly receive myelinated fibers transmitting innoxious information, such as vibration, touch and pressure. ${ }^{31,32}$ Noxious information was transmitted by unmyelinated $\mathrm{C}$ fibers and large subsets of $\mathrm{A} \delta$ fibers. ${ }^{33}$ Large-scale studies verified the important role of glycinergic neurons in the deep dorsal horn. ${ }^{34}$ Consistent with these results, we found that $72.1 \%$ of the GlyT2tdTomato neurons were located at lamina IIi to IV of the dorsal horn, and were mainly innervated by $A \beta$ fibers directly. Besides, some GlyT2-tdTomato neurons were also innervated by $\mathrm{A} \delta$ or $\mathrm{C}$ fibers, suggesting that glycinergic neurons may be also involved in the modulation of noxious information. The elucidation of primary afferents which glycinergic neurons received could enrich our understanding of their roles on gate circuits in the spinal cord. All the above results put further emphasis on future research about the primary afferent fibers innervating the GlyT2+ neurons allowing us to thoroughly study the synaptic plasticity of $\mathrm{GlyT}^{+}$neurons in normal and pathological conditions.

The neurochemical identities of spinal inhibitory neurons deserve comments. Illuminating the concrete phenotypes of glycinergic neurons could provide a basis for understanding the exquisite and complicated modulation on pain information. Previous research has categorized inhibitory interneurons in the spinal cord into four non-overlapped types according to their neurochemical identity, that is, galanin ${ }^{+}, \mathrm{NPY}^{+}, \mathrm{NOS}^{+}$ and dynorphin ${ }^{+}$neurons. ${ }^{35}$ It was also reported that spinal glycinergic neurons, a subtype of spinal inhibitory neurons, expressed parvalbumin (PV), neuropeptide Y (NPY) and galanin (Gal). ${ }^{36}$ Neurons that express nNOS in the spinal cord were thought to be mainly glycinergic neurons instead of GABAergic neurons. Previous research showed that nNOS 
immunostaining cells co-expressed with vGAT buttons which is a marker of both glycinergic and GABAergic neurons. ${ }^{37}$ While recent study applying ISH and single-cell sequencing method pointed out that GABA mRNA did not label nNOS ${ }^{+}$ neurons. ${ }^{36}$ Combined the results of the above studies with our work, we can conclude that GlyT2 positive neurons may be mainly $\mathrm{nNOS}^{+}$neurons. However, one imperative point that should not be overlooked is that a part of $\mathrm{nNOS}^{+}$neurons also express $\mathrm{PKC} \gamma$ which is a marker of excitatory interneurons. ${ }^{38}$ In addition, since activation of $\mathrm{nNOS}^{+}$neurons could alleviate mechanical hyperalgesia, ${ }^{39}$ it is reasonable for us to speculate that GlyT2 positive glycinergic neurons colocalized with nNOS have an imperial role in gating nociceptive signals. ${ }^{3,40}$ $\mathrm{PV}^{+}$neurons are mainly located in lamina II-III of the spinal cord. $^{41}$ Research has shown that the mechanism of $\mathrm{PV}^{+}$neurons in modulating sensation is through GABAergic with glycinergic inhibition. ${ }^{15}$ Equally important, our previous research also showed that $\mathrm{PKC} \gamma$ neurons were gated by glycinergic mixed with GABAergic inhibition. ${ }^{10}$ In addition, most percentages of $\mathrm{PV}^{+}$neurons were labeled with both glycine and GABA. ${ }^{42}$ Despite these neurons co-expressed with gaba14 mRNA, ${ }^{36}$ we could get a conclusion that $\mathrm{PV}^{+}$ neurons were most likely glycinergic and GABAergic which can gate $\mathrm{PKC} \gamma$ neurons. Since $\mathrm{PV}^{+}$neurons also act as a key element in developing hypersensitivity after peripheral nerve injury through GABAergic inhibition, ${ }^{43,44}$ future investigation should attach more importance to illuminating whether GlyT2 positive $\mathrm{PV}^{+}$neurons will also have similar effects on nociceptive information.

Of course, there are still some deficiencies in the present study, due to the restriction of gene CRISPR technology. Compared with the actual expression of the GlyT2 gene, GlyT2-iCre-tdTomato mice may label more GlyT2 ${ }^{+}$ neurons. In addition, some GlyT2 gene may disappear in an early embryonic development. The characteristics of these neurons expressing tdTomato protein require detailed investigation. Equally important, to understand how the spinal allodynia gate works, further experiments on the changes pertaining to the excitability of the glycinergic neurons in pathological condition are needed.

\section{Conclusion}

The present study indicated that spinal glycinergic neurons mainly received primary afferent $A \beta$ fiber inputs; the GlyT2-P2A-iCre and GlyT2-tdTomato mice provided a useful animal model to further investigate the function of the GlyT2 $2^{+}-\mathrm{PKC} \gamma^{+}$feedforward inhibitory circuit in both physiological and pathological conditions.

\section{Acknowledgments}

This study was supported by the National Natural Science Foundation of China (31530090 and 81971058). The authors thank Christopher G. Myers (PhD, Johns Hopkins University) for language review of the manuscript.

\section{Author Contributions}

Xiaolan He, Peng Liu and Xiao Zhang designed the experiments. Xiaolan He, Peng Liu, Xiao Zhang, Zhenhua Jiang and Nan Gu carried out the experiments. Qun Wang and Yan Lu supervised the experiments and analyzed data. All authors made substantial contributions to conception and design, acquisition of data, or analysis and interpretation of data; took part in drafting the article or revising it critically for important intellectual content; agreed to submit to the current journal; gave final approval of the version to be published; and agree to be accountable for all aspects of the work.

\section{Disclosure}

The authors report no conflicts of interest in this work.

\section{References}

1. Todd AJ. Neuronal circuitry for pain processing in the dorsal horn. Nat Rev Neurosci. 2010;11(12):823-836. doi:10.1038/nrn2947

2. Takazawa T, Macdermott AB. Synaptic pathways and inhibitory gates in the spinal cord dorsal horn. Ann N Y Acad Sci. 2010;1198 (1):153-158. doi:10.1111/j.1749-6632.2010.05501.x

3. Foster E, Wildner H, Tudeau L, et al. Targeted ablation, silencing, and activation establish glycinergic dorsal horn neurons as key components of a spinal gate for pain and itch. Neuron. 2015;85 (6):1289-1304. doi:10.1016/j.neuron.2015.02.028

4. Watanabe K, Nakamura M, Iwanami A, et al. Comparison between fetal spinal-cord- and forebrain-derived neural stem/progenitor cells as a source of transplantation for spinal cord injury. Dev Neurosci. 2004;26(2-4):275-287. doi:10.1159/000082144

5. Light AR, Perl ER. Spinal termination of functionally identified primary afferent neurons with slowly conducting myelinated fibers. J Comp Neurol. 1979;186(2):133-150.

6. Lu Y, Perl ER. A specific inhibitory pathway between substantia gelatinosa neurons receiving direct C-fiber input. J Neurosci. 2003;23 (25):8752-8758. doi:10.1523/JNEUROSCI.23-25-08752.2003

7. Lu Y. Modular organization of excitatory circuits between neurons of the spinal superficial dorsal horn (Laminae I and II). J Neurosci. 2005;25(15):3900-3907. doi:10.1523/JNEUROSCI.0102-05.2005

8. Poyatos I, Ponce J, Aragón C, Giménez C, Zafra F. The glycine transporter GLYT2 is a reliable marker for glycine-immunoreactive neurons. Brain Res Mol Brain Res. 1997;49(1-2):63-70. doi:10.1016/S0169-328X(97)00124-1

9. Zeilhofer HU, Studler B, Arabadzisz D, et al. Glycinergic neurons expressing enhanced green fluorescent protein in bacterial artificial chromosome transgenic mice. J Comp Neurol. 2005;482(2):123-141. doi:10.1002/cne.20349

10. Wang Q, Zhang $\mathrm{X}$, He X, et al. Synaptic dynamics of the feed-forward inhibitory circuitry gating mechanical allodynia in mice. Anesthesiology. 2020;132(5):1212-1228. doi:10.1097/ALN.00 00000000003194 
11. Lu Y, Dong H, Gao Y, et al. A feed-forward spinal cord glycinergic neural circuit gates mechanical allodynia. J Clin Invest. 2013;123 (9):4050-4062. doi:10.1172/JCI70026

12. Yaksh TL. Behavioral and autonomic correlates of the tactile evoked allodynia produced by spinal glycine inhibition: effects of modulatory receptor systems and excitatory amino acid antagonists. Pain. 1989;37(1):111-123. doi:10.1016/0304-3959(89)90160-7

13. Miraucourt LS, Dallel R, Voisin DL. Glycine inhibitory dysfunction turns touch into pain through PKCgamma interneurons. PLoS One. 2007;2(11):e1116. doi:10.1371/journal.pone.0001116

14. Miraucourt LS, Moisset X, Dallel R, Voisin DL. Glycine inhibitory dysfunction induces a selectively dynamic, morphine-resistant, and neurokinin 1 receptor-independent mechanical allodynia. J Neurosci. 2009;29(8):2519-2527. doi:10.1523/JNEUROSCI.3923-08.2009

15. Petitjean H, Pawlowski SA, Fraine SL, et al. Dorsal horn parvalbumin neurons are gate-keepers of touch-evoked pain after nerve injury. Cell Rep. 2015;13(6):1246-1257. doi:10.1016/j.celrep.2015.09.080

16. Mali P, Esvelt KM, Church GM. Cas9 as a versatile tool for engineering biology. Nat Methods. 2013;10(10):957-963. doi:10.1038/ nmeth. 2649

17. Wu M, Wei C, Lian Z, et al. Rosa26-targeted sheep gene knock-in via CRISPR-Cas9 system. Sci Rep. 2016;6(1):24360. doi:10.1038/ srep24360

18. Chen CL, Broom DC, Liu Y, et al. Runx1 determines nociceptive sensory neuron phenotype and is required for thermal and neuropathic pain. Neuron. 2006;49(3):365-377. doi:10.1016/j.neuron. 2005.10 .036

19. Liu Y, Abdel Samad O, Zhang L, et al. VGLUT2-dependent glutamate release from nociceptors is required to sense pain and suppress itch. Neuron. 2010;68(3):543-556. doi:10.1016/j.neuron.2010.09.008

20. Zhang X, Gao Y, Wang Q, et al. Riluzole induces LTD of spinal nociceptive signaling via postsynaptic GluR2 receptors. J Pain Res. 2018;11:2577-2586. doi:10.2147/JPR.S169686

21. Duan B, Cheng L, Bourane S, et al. Identification of spinal circuits transmitting and gating mechanical pain. Cell. 2014;159 (6):1417-1432. doi:10.1016/j.cell.2014.11.003

22. Fremeau RT Jr., Voglmaier S, Seal RP, Edwards RH. VGLUTs define subsets of excitatory neurons and suggest novel roles for glutamate. Trends Neurosci. 2004;27(2):98-103. doi:10.1016/j.tins.2003.11.005

23. Carstens EE, Carstens MI, Simons CT, Jinks SL. Dorsal horn neurons expressing NK-1 receptors mediate scratching in rats. Neuroreport. 2010;21(4):303-308. doi:10.1097/WNR.0b013e328337310a

24. Yasaka T, Tiong SY, Hughes DI, Riddell JS, Todd AJ. Populations of inhibitory and excitatory interneurons in lamina II of the adult rat spinal dorsal horn revealed by a combined electrophysiological and anatomical approach. Pain. 2010;151(2):475-488. doi:10.1016/j. pain.2010.08.008

25. Gong S, Doughty M, Harbaugh CR, et al. Targeting Cre recombinase to specific neuron populations with bacterial artificial chromosome constructs. $J$ Neurosci. 2007;27(37):9817-9823. doi:10.1523/ JNEUROSCI.2707-07.2007

26. Gong S, Zheng C, Doughty ML, et al. A gene expression atlas of the central nervous system based on bacterial artificial chromosomes. Nature. 2003;425(6961):917-925. doi:10.1038/nature02033

27. Wang F, Qi LS. Applications of CRISPR genome engineering in cell biology. Trends Cell Biol. 2016;26(11):875-888. doi:10.1016/j. tcb.2016.08.004

28. Hossaini M, French PJ, Holstege JC. Distribution of glycinergic neuronal somata in the rat spinal cord. Brain Res. 2007;1142:61-69. doi:10.1016/j.brainres.2007.01.078

29. Todd AJ, Spike RC. The localization of classical transmitters and neuropeptides within neurons in laminae I-III of the mammalian spinal dorsal horn. Prog Neurobiol. 1993;41(5):609-645.
30. Lu VB, Biggs JE, Stebbing MJ, et al. Brain-derived neurotrophic factor drives the changes in excitatory synaptic transmission in the rat superficial dorsal horn that follow sciatic nerve injury. $J$ Physiol. 2009;587(Pt 5):1013-1032. doi:10.1113/jphysiol.2008.166306

31. Lu Y. Synaptic wiring in the deep dorsal horn. focus on "Local circuit connections between hamster laminae III and IV dorsal horn neurons". J Neurophysiol. 2008;99(3):1051-1052. doi:10.1152/jn.000 27.2008

32. Schneider SP. Functional properties and axon terminations of interneurons in laminae III-V of the mammalian spinal dorsal horn in vitro. J Neurophysiol. 1992;68(5):1746-1759. doi:10.1152/jn.1992. 68.5.1746

33. Braz J, Solorzano C, Wang X, Basbaum AI. Transmitting pain and itch messages: a contemporary view of the spinal cord circuits that generate gate control. Neuron. 2014;82(3):522-536. doi:10.1016/j. neuron.2014.01.018

34. Cronin JN, Bradbury EJ, Lidierth M. Laminar distribution of GABAA- and glycine-receptor mediated tonic inhibition in the dorsal horn of the rat lumbar spinal cord: effects of picrotoxin and strychnine on expression of Fos-like immunoreactivity. Pain. 2004;112(1-2):156-163. doi:10.1016/j.pain.2004.08.010

35. Boyle KA, Gutierrez-Mecinas M, Polgar E, et al. A quantitative study of neurochemically defined populations of inhibitory interneurons in the superficial dorsal horn of the mouse spinal cord. Neuroscience. 2017;363:120-133. doi:10.1016/j.neuroscience.2017.08.044

36. Häring M, Zeisel A, Hochgerner H, et al. Neuronal atlas of the dorsal horn defines its architecture and links sensory input to transcriptional cell types. Nat Neurosci. 2018;21(6):869-880. doi:10.1038/s41593018-0141-1

37. Sardella TC, Polgar E, Watanabe M, Todd AJ. A quantitative study of neuronal nitric oxide synthase expression in laminae I-III of the rat spinal dorsal horn. Neuroscience. 2011;192:708-720. doi:10.1016/j. neuroscience.2011.07.011

38. Hughes AS, Averill S, King VR, Molander C, Shortland PJ. Neurochemical characterization of neuronal populations expressing protein kinase $\mathrm{C}$ gamma isoform in the spinal cord and gracile nucleus of the rat. Neuroscience. 2008;153(2):507-517. doi:10.10 16/j.neuroscience.2008.01.082

39. Huang J, Polgar E, Solinski HJ, et al. Circuit dissection of the role of somatostatin in itch and pain. Nat Neurosci. 2018;21(5):707-716. doi:10.1038/s41593-018-0119-z

40. Zhao J, Wood JN. Glycine at the gate-from model to mechanism. Neuron. 2015;85(6):1152-1154. doi:10.1016/j.neuron.2015.03.012

41. Antal M, Polgár E, Chalmers J, et al. Different populations of parvalbumin- and calbindin-D28k-immunoreactive neurons contain GABA and accumulate $3 \mathrm{H}-\mathrm{D}$-aspartate in the dorsal horn of the rat spinal cord. J Comp Neurol. 1991;314(1):114-124. doi:10.1002/ cne.903140111

42. Laing I, Todd AJ, Heizmann CW, Schmidt HH. Subpopulations of GABAergic neurons in laminae I-III of rat spinal dorsal horn defined by coexistence with classical transmitters, peptides, nitric oxide synthase or parvalbumin. Neuroscience. 1994;61(1):123-132. doi:10.1016/03064522(94)90065-5

43. Hughes DI, Sikander S, Kinnon CM, et al. Morphological, neurochemical and electrophysiological features of parvalbumin-expressing cells: a likely source of axo-axonic inputs in the mouse spinal dorsal horn. J Physiol. 2012;590(16):3927-3951. doi:10.1113/jphysiol.2012.235655

44. Boyle KA, Gradwell MA, Yasaka T, et al. Defining a spinal microcircuit that gates myelinated afferent input: implications for tactile allodynia. Cell Rep. 2019;28(2):526-540.e526. doi:10.1016/j.celrep. 2019.06.040 


\section{Publish your work in this journal}

The Journal of Pain Research is an international, peer reviewed, open access, online journal that welcomes laboratory and clinical findings in the fields of pain research and the prevention and management of pain. Original research, reviews, symposium reports, hypothesis formation and commentaries are all considered for publication. The manuscript management system is completely online and includes a very quick and fair peer-review system, which is all easy to use. Visit http:// www.dovepress.com/testimonials.php to read real quotes from published authors. 